\title{
Editorial: The Impact of Open Science for Evaluation of Volcanic Hazards
}

\author{
Elisa Trasatti ${ }^{1 *}$, Fidel Costa $^{2}$ and Michelle Parks ${ }^{3}$ \\ ${ }^{1}$ Istituto Nazionale di Geofisica e Vulcanologia, Osservatorio Nazionale Terremoti, Rome, Italy, ${ }^{2}$ Asian School of the Environment \\ and Earth Observatory of Singapore, Nanyang Technological University, Singapore, Singapore, ${ }^{3} / c e l a n d i c$ Meteorological Office, \\ Reykjavik, Iceland
}

Keywords: volcanic hazards and risk, remote sensing, natural hazards, open science, findable accessible interoperable and reusable principles, database (all types), volcanic unrest, eruptions

Editorial on the Research Article

\section{The Impact of Open Science for Evaluation of Volcanic Hazards}

The Open Science paradigm addresses the scientific process of producing and sharing knowledge and data as early as possible in the research development, through digital and collaborative technology. It includes findable and interoperable data, access to data processing platforms, and sharing of research products within the scientific community and with stakeholders. Open Science increases the quality and impact of science by fostering reproducibility and interdisciplinarity.

The growing interest for more Open Science in the Earth Sciences has stimulated this Research Topic that aimed at collecting contributions from the Volcanological scientific community. Anticipating volcanic eruptions and mitigating their associated hazards and risks can greatly benefit from the Open Science approach. In particular, proper management of volcanic crises, such as during unrest and eruption, needs rapid access to scientific data and results by stakeholders and decision-makers.

The contributions of this issue range from data-driven applications for volcanic hazard mitigation (Beauducel et al.; Coppola et al.; Fujita et al.; Tierz; Whitty et al.) to original research studies (Aranzulla et al.; Bignami et al.).

Fujita et al. present a new database and management system of volcanological information in Japan. It includes four themes focusing on observational data, forecasting of events, implementation

OPEN ACCESS

Edited and reviewed by: Valerio Acocella,

Roma Tre University, Italy

*Correspondence:

Elisa Trasatti

elisa.trasatti@ingv.it

Received: 28 January 2021

Accepted: 02 February 2021

Published: 19 March 2021

Citation:

Trasatti E, Costa F and Parks M (2021) Editorial: The Impact of Open Science for Evaluation of Volcanic Hazards. Front. Earth Sci. 9:659772. doi: 10.3389/feart.2021.659772 of hazard mitigation measures, and a data-sharing system. This data-sharing system is named the Japan Volcanological Data Network and will serve as a platform for the analysis of branch nodes of probabilistic event trees for volcanic crises in the coming decades in Japan.

In a prospective-type article, Tierz discusses the importance of open databases for the volcanological community to be able to perform robust probabilistic volcanic hazard assessments. Given the complexity of volcanic processes and the relative scarcity of information on past eruptions, it is critical to have systems in place that allow for discoverability and accessibility to volcanological data. The author also clarifies some misunderstanding of the use and meaning of long term probabilistic volcanic hazard assessment.

Beauducel et al. have developed an open source software system called WebObs aimed at facilitating the tasks of data storage, visualization, and interpretation of volcanological observatories. The system allows efficient real-time access to monitoring data, metadata, modeling and estimation of uncertainties, which are fundamental for an efficient interpretation of the monitored signals. It supports data analysis and exchange between researchers, engineers, and technicians during periods of volcanic unrest or quiescence. WebObs is also open for further development and enhanced data processing. 
Aranzulla et al. present new methodology for modeling tropospheric delays with the aim of calculating tropospheric corrections for DInSAR (Differential Interferometric Synthetic Aperture Radar) data. Removal of atmospheric artifacts from interferograms remains a challenging task - especially in areas with highly variable weather conditions and steep topography, such as in the vicinity of stratovolcanoes. The authors test an improved tomography algorithm to estimate the wet-refractivity field on a synthetic dataset and also apply the method to correct Sentinel-1 interferograms at Mt Etna during 2015, incorporating water vapor measurements derived from MODIS instruments on-board Terra and Aqua satellites. The inclusion of MODIS data improves the tomographic resolution and the technique is successful in modeling the large-scale atmospheric effects.

Whitty et al. analyze open access data from the permanent air quality monitoring networks at the Island of Hawai' $i$, obtaining measurements of $\mathrm{SO}_{2}$ and $\mathrm{PM}_{2.5}$ for about 12 years. Additional air quality data were collected during the 2018 lower East Rift Zone eruption of Kilauea through a low-cost $\mathrm{PM}_{2.5}$ network. The 2018 eruption caused severe excess of the air quality threshold for $\mathrm{PM}_{2.5}$ even $100 \mathrm{~km}$ away from Kilauea. Data from the low-cost sensor network correlated well with data from permanent instruments, confirming that these low-cost sensors provide robust monitoring means with the added value of being an open access source of readily-available information to the public for community awareness toward air quality.

Coppola et al. present a web-based and open source system called MIROVA (Middle Infrared Observation of Volcanic Activity) that allows automatic volcano hot spot detection using Moderate Resolution Imaging Spectroradiometer. The system is able to detect, locate and quantify thermal anomalies in near real-time on over 200 volcanoes worldwide. MIROVA is currently used by several volcano observatories for daily monitoring activities and reporting.

Bignami et al. exploit multi-sensor images from mostly open access missions to retrieve key elements for volcanic crises management, such as lava flow patterns and volcanic source parameters related to the effusive eruption of Fogo volcano, Cape Verde, between November 2014 and January 2015. The main outcome of the work is the application of a new automatic change detection technique for estimating the lava field and its temporal evolution, combining the SAR intensity and the interferometric SAR coherence. These data are applied for the first time for lava mapping, providing an example of using the multi-temporal interferometric SAR coherence to automatically monitor lava flow evolution during an emergency phase.

The papers included in this Research Topic highlight the importance of making a bigger effort in global sharing of data and methods in an open way, showing the criticality for volcanic risk management in all its phases (e.g., before and during eruptions). Terrestrial and satellite monitoring techniques offer timely measurements for detecting volcanic activity at a global scale. Access to data, along with the availability of open processing tools and environments, and rapid sharing of results are vital for volcanic hazard assessment today and for growing future applications of data integration.

\section{AUTHOR CONTRIBUTIONS}

All authors contributed equally to this editorial and to the Research Topic management.

\section{ACKNOWLEDGMENTS}

We thank all authors for their contributions, the reviewers for valuable comments, and the Frontiers Editorial Office for improving the layout of this Research Topic.

Conflict of Interest: The authors declare that the research was conducted in the absence of any commercial or financial relationships that could be construed as a potential conflict of interest.

Copyright (c) 2021 Trasatti, Costa and Parks. This is an open-access article distributed under the terms of the Creative Commons Attribution License (CC $B Y)$. The use, distribution or reproduction in other forums is permitted, provided the original author(s) and the copyright owner(s) are credited and that the original publication in this journal is cited, in accordance with accepted academic practice. No use, distribution or reproduction is permitted which does not comply with these terms. 